\title{
Dinâmicas Geoeconômicas do BNDES e seu papel na formação dos Complexos Agroindustriais no Brasil
}

Dinâmicas Geoeconômicas do BNDES e seu papel na formação dos Complexos

Agroindustriais no Brasil

Dinámica Geoeconómica del BNDES y su papel en la formación de Complejos Agro-industriales en Brasil

Geoeconomic Dynamics of BNDES and uit role in the construction on agricultural complexes in Brazil

\section{Alessandro Viceli e Marlon Clóvis Medeiros}

\section{CpenEdition}

Journals

Edição electrónica

URL: http://journals.openedition.org/espacoeconomia/18636

DOI: 10.4000/espacoeconomia.18636

ISSN: 2317-7837

Editora

Núcleo de Pesquisa Espaço \& Economia

Refêrencia eletrónica

Alessandro Viceli e Marlon Clóvis Medeiros, «Dinâmicas Geoeconômicas do BNDES e seu papel na formação dos Complexos Agroindustriais no Brasil», Espaço e Economia [Online], 20 | 2020, posto online no dia 29 dezembro 2020, consultado o 29 janeiro 2021. URL: http://journals.openedition.org/ espacoeconomia/18636; DOI: https://doi.org/10.4000/espacoeconomia.18636

Este documento foi criado de forma automática no dia 29 janeiro 2021.

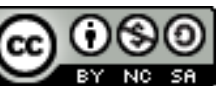

Espaço e Economia - Revista brasileira de geografia econômica est mise à disposition selon les termes de la licence Creative Commons Attribution - Pas d'Utilisation Commerciale - Partage dans les Mêmes Conditions 4.0 International. 


\section{Dinâmicas Geoeconômicas do BNDES e seu papel na formação dos Complexos Agroindustriais no Brasil}

Dinâmicas Geoeconômicas do BNDES e seu papel na formação dos Complexos

Agroindustriais no Brasil

Dinámica Geoeconómica del BNDES y su papel en la formación de Complejos

Agro-industriales en Brasil

Geoeconomic Dynamics of BNDES and uit role in the construction on agricultural

complexes in Brazil

Alessandro Viceli e Marlon Clóvis Medeiros

\section{Introdução}

1 Considerando que o Banco Nacional de Desenvolvimento Econômico e Social (BNDES) é a principal instituição financeira que promove investimentos nos setores produtivos no Brasil, possibilitando uma série de dinâmicas geoeconômicas, o presente artigo possui como objetivo abordar como se deu o processo de formação dos Complexos Agroindustriais do país e a influência do BNDES em todo esse processo, focando a análise até os anos $1980^{1}$. É importante destacar que os Complexos Agroindustriais (CAI's) ${ }^{2}$ representam a junção interdependente entre agricultura e indústria, à medida em que a agricultura precisa de insumos industrializados para produzir, e consequentemente, a indústria processa a matéria-prima oriunda da agricultura (KAGEYAMA, 1987; SILVA, 1991), possuindo então uma estreita ligação com os processos de modernização e industrialização da agricultura brasileira.

2 Desta forma, frente a ausência de discussões teóricas que abordem a relação entre o BNDES e a gênese dos CAI's, o presente artigo se propõe a abordar essa problemática, incorporando na análise os elementos da macroeconomia, que muitas vezes são negligenciados pela Geografia. Para tal proposta, optou-se por utilizar a pesquisa 
bibliográfica como instrumento metodológico, focando em trabalhos acadêmicos (teses, artigos, dissertações, capítulos de livros) que trouxessem elementos e dados sobre o BNDES, formação dos CAI's, conjuntura política e econômica no Brasil durante o período abordado, juntamente com informações obtidas no banco de dados do tanto IBGE (Instituto Brasileiro de Geografia e Estatística).

3 Tal artigo foi estruturado em duas partes. Na primeira o foco é direcionado para a formação do $\mathrm{BNDES}^{3}$, sendo colocado em evidência todo o contexto político e econômico que resultou na sua criação e como foi se dando o processo de direcionamento dos investimentos dessa instituição, que por sinal seriam as bases que sustentariam os CAI's. Já na segunda parte, é abordado a gênese e desenvolvimento desses complexos e como o BNDES direcionou seus fluxos de capital tanto para esse setor produtivo quanto para os demais setores que faziam parte da mesma cadeia produtiva.

4 Portanto, em linhas gerais, o texto expõe a aproximação entre o BNDES e os CAI's, a partir de uma perspectiva geográfica.

\section{Criação do BNDES e as bases para a formação dos Complexos Agroindustriais}

5 Não há como tratarmos dos complexos agroindustriais e do BNDES no Brasil sem destacarmos a transformação que ocorreu na economia brasileira a partir de 1930, momento em que o país atravessava a fase "b" (recessiva) do $3^{\circ}$ Kondratiev (RANGEL, 1983), cuja conjuntura "provocou nova relação mundo-nações: a Inglaterra abandonou definitivamente o livre-cambismo e houve fechamento dos mercados nacionais nos EUA, Alemanha, França e na periferia do sistema capitalista (substituições de importações se aceleraram) (MAMIGONIAN, 1999, p.155)". Ainda sobre esse contexto, tendo como parâmetro o movimento da dualidade da economia brasileira, Rangel (1990, p.35) faz a seguinte análise:

6 Nossa industrialização, nos quadros da Terceira Dualidade, isto é, sob o comando do pacto de poder entre o latifúndio feudal e o nascente capitalismo industrial, como sócio maior e menor, respectivamente, fez-se através de surtos cíclicos aproximadamente decenais - obviamente aparentados dos ciclos de Juglar. Cada um desses ciclos liquidava o atraso relativo de um dos "setores" em que as mudanças institucionais iam permitindo dividir o sistema econômico nacional. Em 1930, quando, já no fundo da fase $\mathrm{b}$ do Terceiro Kondratiev, o movimento industrializador ganhou momento decisivo [...].

7 Portanto, a partir da influência de elementos oriundos do centro do sistema capitalista, principalmente da crise de 1929, somados com as especificidades econômicas e políticas internas, o Brasil começa de forma efetiva um processo industrial de substituição de importações, diferente das conjunturas das dualidades anteriores (RANGEL, 1981). A revolução de 1930 foi a materialização do pacto de poder entre o latifúndio semifeudal e a burguesia industrial (anteriormente burguesia comercial), e desta forma tal pacto passou a nortear de forma intensa as ações políticas no Estado brasileiro, sob comando de Getúlio Vargas. É importante ressaltar que o cenário de crise das exportações do café brasileiro, pela queda da demanda estrangeira, e a consequente queda na obtenção de divisas para a importação de produtos manufaturados, foi um dos elementos conjunturais preponderantes para a gênese do processo de substituição de importações. 
Ao mesmo tempo em que gerou a necessidade de fabricação de determinados bens de consumo para a população brasileira, possibilitou uma oportunidade de investimento, resultando em uma transferência de capitais acumulados nas atividades agropecuárias para as atividades do setor industrial.

Como forma de superar os impactos da crise de 1929 e dar seguimento à nova estrutura estabelecida pelo novo pacto de poder, o governo de Vargas atuou no sentido estruturar uma série de políticas e órgãos que permitissem o fortalecimento da indústria nacional, uma vez que nesse período a indústria se tornou sinônimo de desenvolvimento econômico. Foram as mudanças institucionais e determinadas ações políticas promovidas por Getúlio Vargas que possibilitaram o intenso início do processo de industrialização brasileiro via substituição de importações e sua consequente condução, dentre as quais se destacam: 1930 - criação do Ministério do Trabalho, Indústria e Comércio; 1933 - criação do Departamento Nacional do Trabalho e o Instituto do Açúcar e do Álcool; 1934 - Reforma Tributária; 1935 - assinatura do tratado com os Estados Unidos para a importação de bens de capital; 1937 - Carteira de Crédito Agrícola e Industrial do Banco do Brasil; 1940 - Companhia Vale do Rio Doce; 1941 Companhia Siderúrgica Nacional; 1943 - Consolidação das Leis Trabalhistas. A criação de tais instituições e ações políticas demonstram claramente a proposta governista voltada para a indústria, e principalmente a postura nacional desenvolvimentista de Getúlio Vargas.

9 Nesse mesmo sentido, Vargas seguia com uma política externa, de forma a intercalar relações com os EUA e a Alemanha, angariando investimentos e acordos comerciais com ambos, sempre buscando colocar os interesses nacionais a frente. No entanto, durante e após a $2^{\mathrm{a}}$ Guerra a postura nacionalista externa do governo Vargas teve de ser deixada de lado, mantendo-a somente no plano interno do país, em virtude das relações e por certa pressão dos próprios americanos e seus interesses geoeconômicos e geopolíticos (DINIZ, 2004).

10 Com a deposição de Getúlio Vargas em 1945, pôs fim ao chamado Estado Novo, dando lugar, após as eleições deste mesmo ano, ao Marechal Eurico Gaspar Dutra, pertencente ao quadro do PSD (Partido Social Democrático). Em relação ao período de governo de Dutra (1946-1951), baseando-nos nas colocações de Hippolito (1985), é possível apontar que ele foi caracterizado por duas fases, sendo a $1^{\mathrm{a}}$ Fase: (1946 a 1947) - caracterizado por buscar novamente as bases do liberalismo e a $2^{\mathrm{a}}$ Fase: (1947-1951) - dissolução dos pressupostos liberais de toda a plataforma do governo e retomada do intervencionismo estatal na balança comercial e principalmente na política cambial.

11 Na sua primeira fase, a postura do governo Dutra foi a de seguir os preceitos liberais expostos a partir do Tratado de Bretton Woods, pautados na crença de que os Estados Unidos continuariam a manter uma relação próxima com o Brasil, durante o pós-guerra (DRAIBE, 1985). No entanto, o que se mostrou foram os EUA mais preocupado em financiar a reconstrução dos países europeus, pois acreditavam que seria mais vantajoso, do ponto de vista da acumulação de capital, o estreitamento com os países que estavam se reerguendo (BENEVIDES, 1981).

12 Elementos como a escassez internacional de dólares, saldos positivos em moedas não conversíveis e desperdício de divisas conversíveis, ajudaram a agravar ainda mais a situação do Brasil até 1947. Essa situação trazia impactos no cotidiano da vida do brasileiro, uma vez que com a intensificação da crise cambial e da inflação, o poder de 
compra da população foi afetado e isso gerava outras reações em cadeia, afetando a esfera política do país (BENEVIDES, 1981; HIPPOLITO, 1985).

13 Estabelecido este cenário, coube ao governo de Dutra voltar à postura intervencionista do Estado para com a dinâmica econômica do país. Neste sentido, adotou-se medidas para a contenção de produtos importados, de determinadas categorias e controle rígido da estrutura cambial. De certa forma, isso é que deu uma maior sustentação para uma volta à pauta de avanço da industrialização brasileira, que havia desacelerado em 1946 e 1947 (BENEVIDES, 1985).

14 Durante este período, o governo colocou em prática a flutuação cambial, que por sua vez foi um dos elementos que influenciou consideravelmente na dinâmica dos setores industrial e agrícola, na medida em que implicava em uma transferência de renda agropecuária para o setor industrial, principalmente no período de 1946 à 1964 (BACHA, 2012). Ainda nesse período, foram criadas várias comissões com o intuito de realizarem estudos e definirem projetos, como forma de angariar capitais estrangeiros para investimento em desenvolvimento econômico nacional, mas tais comissões não se efetivaram (DINIZ, 2004). Foi somente em 1950, durante uma Conferência de Embaixadores, que a diplomacia brasileira conseguiu uma articulação externa que deu origem à Comissão Mista Brasil Estados Unidos (CMBEU) que, com a volta de Getúlio Vargas no cargo de Presidente, tratou de dar prosseguimento ao projeto de financiamento proposto por essa comissão, resultando em 1951 no acordo entre o BIRD, Eximbank e o governo do Brasil (DINIZ, 2004). Basicamente, "a finalidade da CMBEU consistia na elaboração de projetos com vistas ao financiamento, concentrando atenção na superação dos entraves econômicos ao processo de industrialização (DINIZ, 2004, p. 9).

15 A partir desse acordo com essas instituições financeiras, visando o aporte de capitais externos, foi estabelecido uma série de condições para viabilizar os projetos da CMBEU, incluindo o comprometimento de recursos internos (DINIZ, 2004; COUTO; TRINTIN, 2012). Desta forma, "para o cumprimento dessas exigências, a Lei 1628, de 20 de junho de 1952, criou um novo órgão; o Banco Nacional de Desenvolvimento Econômico (BNDE) (DINIZ, 2004, p.10)". Analisando os primeiros anos de atuação do BNDE, Lessa (1983) destaca que esta instituição tinha uma orientação para viabilizar principalmente os projetos de desenvolvimento industrial no Brasil, mas no seu primeiro quinquênio, este banco financiou apenas projetos de infraestrutura ${ }^{4}$ (DINIZ, 2004).

Em relação ao aporte de capitais do BNDE neste período, Couto e Trintin (2012) afirmam que os valores investidos não eram expressivos. Tal quadro de fluxo de capital externo no país nestes primeiros anos da década de 1950, foi resultado da própria postura nacionalista de Vargas, que fez romper as relações entre o Banco Mundial e o Brasil. Já para Diniz (2004), o governo americano não queria financiar projetos de desenvolvimento industrial no Brasil, pois isso iria fortalecer a posição nacionalista de Vargas. No entanto, de acordo com Diniz (2004), essa mesma ausência de recursos externos acabou dando maior liberdade para a equipe técnica que trabalhava no BNDE, o que resultou na cooperação junto a Comissão Econômica para a América Latina (CEPAL), criando em 1953, o grupo Misto BNDE-CEPAL, com claras influências das propostas cepalinas de desenvolvimento econômico. Ainda de acordo com essa autora, os projetos elaborados por esse grupo tinham uma abordagem mais global, diferente da Comissão Mista que era setorial (DINIZ, 2004). 
17 Com a chegada de Juscelino Kubitschek (JK) à presidência, passam a ser instrumentalizadas novas propostas políticas para a tentativa de alteração da estrutura econômica do país. "O compromisso de Jucelino Kubitschek era de acelerar o crescimento e implantar a indústria moderna no país (DINIZ, 2004, p.19)”. Foi a partir da concepção do Plano de Metas do governo JK, que o Estado brasileiro demonstrou quais seriam os passos a serem dados rumo a uma nova estrutura produtiva, visando acelerar o crescimento econômico brasileiro. Esse plano foi elaborado a partir de diagnósticos da economia brasileira, realizados de forma conjunta pelo BNDE e estudiosos vinculados a CEPAL (RABELO, 2008). A ideia era de implantar no país uma infraestrutura que pudesse viabilizar o real desenvolvimento dos mais diversos setores da economia, englobando os transportes, alimentação, educação, energia e indústrias de base. Afirmava-se perante a sociedade brasileira que através desse plano o Brasil cresceria “50 anos em 5".

Para a execução do plano foram estabelecidas metas para todos os setores colocados em pauta, sendo vinculados a eles as determinadas ações que deveriam ser efetivadas. Mas os principais programas e incentivos foram direcionados para o setor industrial e de forma secundária a agricultura acabou se beneficiando de tais medidas. Diante disso a indústria, e paulatinamente a agricultura, usufruiriam de todo o aparelhamento que estava sendo construído no setor da energia ${ }^{5}$, o que possibilitaria a expansão da plataforma produtiva desses dois setores.

19 Em se tratando da expansão da malha rodoviária brasileira, como uma das ações do Plano de Metas, esta medida proporcionou também a intensificação do processo de expansão da fronteira agrícola em várias partes do país, incorporando novos espaços para a dinâmica de acumulação capitalista. Paralelamente, essa expansão da fronteira agrícola, impactou no total produzido por este setor. A respeito disso, Bacha (2012, p. 163) nos demonstra com bastante clareza esse processo, utilizando como exemplo o Estado do Paraná:

20 Esse Estado tinha, em 1940, 64.397 estabelecimentos agropecuários com área total de 6.252.480 hectares. Em 1950, já eram 89.461 estabelecimentos agropecuários com área total de 8.032.743 hectares. Em 1960, eram 269.146 estabelecimentos agropecuários com área total de 11.384.934 hectares. Se consideradas apenas as áreas plantadas com lavouras temporárias e permanentes no Paraná, tem-se que elas eram 764.370 hectares em 1940, passando a 1.358.222 hectares em 1950 e para 3.440.971 hectares em 1960. [...] No período de 1950 a 1960, a expansão da área plantada com lavouras permanentes e temporárias no Paraná foi equivalente a $22 \%$ do aumento ocorrido em todo o Brasil.

21 Diante disso, apesar de certa ampliação da fronteira agrícola, a modernização da estrutura econômica do país, gerada pelo Plano de Metas, acabou pressionando a agricultura a ampliar a sua produção, uma vez que por intermédio do avanço da industrialização e consequente intensificação da urbanização, a população urbana necessitaria de cada vez mais alimentos (MEDEIROS, 2006, p.56). É justamente neste ponto de intensificar a aproximação entre a agricultura e a indústria, que se concentravam os esforços. Ao longo dos anos 50 a agricultura brasileira já passava a incorporar na sua estrutura produtiva a utilização de novas máquinas e insumos para a produção. No entanto, todo esse novo padrão tecnológico era importado, o que influenciava na balança comercial do país, aprofundando o processo de evasão de divisas. Em sua análise, Delgado (1985, p.33) enfatiza que esse é o primeiro período de 
real mudança na base técnica da agricultura, conforme podemos ver no seguinte excerto:

O primeiro momento do processo de modernização agropecuária se caracteriza, grosso modo, pela elevação dos índices de tratorização e consumo de NPK, estimulada e facilitada pelo governo e empresas norte-americanas. Introduz-se nessa primeira década de inovações, que é basicamente a década dos 50 , um novo padrão tecnológico para a produção rural com base na importação de meios de produção industriais. A demanda de insumos é atendida por importações.

Desta forma, o Plano de Metas se prestava à tentativa de internalizar a produção de alguns desses insumos que estavam sendo introduzidos de forma intensa na produção agrícola. "Só com o Plano de Metas, do período Kubitschek, foi possível realizar a meta para fertilizantes, tendo a produção nacional sido consideravelmente fortalecida (GRAZIANO DA SILVA, 1996, p.20)". Além da produção desses insumos, foi efetivada a implantação de indústrias para a fabricação de maquinários (não motorizados) dentre outros produtos. Sobre esse avanço das forças produtivas direcionadas para a agricultura, Muller $(1989$, p.29) faz a seguinte consideração:

Neste período surgem novas indústrias, como a que produz moinhos para o processamento de produtos agrícolas, a de arados reversíveis, máquinas de semear, fertilizadores e veículos agrícolas não motorizados. Havia ainda, se bem que em escala diminuta, a produção de fertilizantes químicos, sendo que a produção maior era feita com matérias-primas de origem vegetal e animal.

Ao tratarmos das indústrias que forneciam equipamentos para a agricultura, destacamos que, para instrumentalizar as ações dentro do Plano de Metas, foram criados Grupos Executivos que atuavam junto ao BNDE, em que tais grupos possuíam funções de "dimensionar programas setoriais para atividades industriais prioritárias, baixar normas e conceder estímulos e, para tanto, possuíam amplitude variável de poderes (DINIZ, 2004, p.24)". Dentre esses grupos setoriais, havia o Grupo Executivo da Indústria de Máquinas Agrícolas e Rodoviárias (GEIMAR) (DINIZ, 2004), que representava essa atuação conjunta entre agricultura e indústria, em cuja articulação era norteada pelo BNDE. Nesse período, é imprescindível detalharmos que para a materialização das ações do Plano de Metas ${ }^{6}$, foi necessário a alocação de grandes volumes de capital estrangeiro, uma vez que o país não possuía reservas o bastante para executar os audaciosos movimentos do plano (RABELO, 2008). Ademais, conforme ressalta Singer (1982) o Estado teve de lançar mão de mecanismos para efetivar uma poupança forçada, que basicamente foi instrumentalizada a partir da adoção de novos impostos e novas alíquotas no Imposto de Renda. Tudo isso como forma de se obter capital necessário para a continuidade do plano.

De acordo com a afirmação exposta acima, podemos ver as proporções de capital alocadas para a efetivação do Plano de Metas, e para os principais setores para onde foram direcionados os investimentos. Na tabela abaixo, veremos exatamente para onde foram dirigidos os recursos financeiros do BNDE para os diversos setores da economia brasileira. 
Tabela 01 - Valor da colaboração autorizada (Cr\$ milhões correntes) junto ao BNDE de acordo com os setores da atividade econômica

\begin{tabular}{|c|c|c|c|c|c|c|c|c|c|c|c|c|c|}
\hline SETORES & 1952 & 1953 & 1954 & 1955 & 1956 & 1957 & 1958 & 1959 & 1960 & 1961 & 1962 & TOTAL & $\begin{array}{c}\% \\
\text { PART. }\end{array}$ \\
\hline TRANSPORTES & $1.181,0$ & 856,9 & $2.310,0$ & $1.017,0$ & $4.882,8$ & $1.629,6$ & - & $1.865,6$ & 478,4 & - & - & $14.221,3$ & 22,5 \\
\hline $\begin{array}{c}\text { ENERGIA } \\
\text { ELÉTRICA }\end{array}$ & - & 371,8 & 407,7 & $1.333,9$ & 659,0 & $4.647,1$ & $5.548,8$ & $2.195,3$ & $1.366,6$ & $8.512,8$ & $3.709,3$ & $28.752,3$ & 45,5 \\
\hline INDÚSTRIAS & - & 230,0 & 233,3 & 195,7 & 273,1 & $1.079,1$ & $4.166,1$ & $2.956,1$ & $4.801,5$ & 965,7 & $2.916,0$ & $17.816,6$ & 28,2 \\
\hline $\begin{array}{c}\text { SETORES } \\
\text { COMPLEMENTARES } \\
\text { DA ATIVIDADE } \\
\text { AGRICOLA }\end{array}$ & - & 27,0 & 46,9 & 46,0 & 289,0 & 278,1 & 350,9 & 143,0 & 53,5 & 771,0 & 386,0 & $2.391,4$ & 3,8 \\
\hline \begin{tabular}{c} 
TOTAL \\
\hline
\end{tabular} & $\mathbf{1 . 1 8 1 , 0}$ & $\mathbf{1 . 4 5 5 , 7}$ & $\mathbf{2 . 9 9 8 , 0}$ & $\mathbf{2 . 5 9 2 , 6}$ & $\mathbf{6 . 1 0 3 , 9}$ & $\mathbf{7 . 6 3 3 , 9}$ & $\mathbf{1 0 . 0 6 5 , 8}$ & $7.160,0$ & $\mathbf{6 . 7 0 0 , 0}$ & $\mathbf{1 0 . 2 4 9 , 5}$ & $\mathbf{7 . 0 1 1 , 3}$ & $\mathbf{6 3 . 1 8 1 , 7}$ & $\mathbf{1 0 0 , 0}$ \\
\hline
\end{tabular}

Fonte: Tavares et al. (2010)

A tabela 01 nos mostra que a maior parte dos recursos do BNDE foram direcionados para o setor de energia elétrica, principalmente para a construção da Usina de Três Marias (DINIZ, 2004), que se justifica pelo fato de que sem uma boa estrutura desse setor, o processo de industrialização ficaria comprometido. No que se refere a indústria em 1958, um grande montante de capital é direcionado a Usiminas e, em 1960, o BNDE financiou o projeto Cosipa, absorvendo quase que a totalidade dos recursos desse ano (DINIZ, 2004).

Esta proporção de investimento por setor nos dá a ideia da pretensão de fortalecer o setor industrial brasileiro, que neste período ocupou a segunda posição na obtenção de capital do BNDE, uma vez que "havia ampliado o mercado interno, o que permitia a instalação de plantas industriais maiores, assegurando a conquista de uma importante massa de economias de escala (SOUZA, 2008, p.32)".

No que se refere aos setores complementares da atividade agrícola, ele obteve apenas $3,8 \%$ do total de capital liberado pelo BNDE durante o período de 1952 a 1962. Tais setores eram representados pelos matadouros industriais, armazéns, silos e frigoríficos (TAVARES et al., 2010), que não drenaram os intensos fluxos de capital neste período, já que a prioridade nos investimentos era nos setores da indústria, transporte e energia.

Em termos relativos a números do setor industrial, após a execução das ações do Plano de Metas, podemos ver o seguinte cenário de acordo com as constatações de Souza (2008, p.33-34):

Se se toma a média dos anos 1954-55 como base, verifica-se que até 1958-1959 os investimentos aumentaram $145 \%$ no ramo de material elétrico e de comunicação e $764 \%$ no ramo de material de transporte. Quanto à sua participação no valor da produção industrial, o índice se elevou de uma cifra desprezível no levantamento de 1949 para uma de $12,56 \%$ em 1962. Enquanto isso, no mesmo período, reduziu-se em $23 \%$ o investimento no ramo têxtil e em $7 \%$ no ramo de produtos alimentícios (ou seja, os dois principais ramos do setor IIa, qualitativa e quantitativamente) e no ramo de vestuário houve um pequeno aumento (15\%) se comparado com a evolução dos ramos do setor IIb. Isso se traduziu numa queda significativa da participação dos ramos representativos do setor IIa no valor da produção industrial: de 55,03\% em 1949 para $34,80 \%$ em 1962.

Atrelado a essa ampliação da plataforma produtiva do setor industrial brasileiro, houve um movimento de intensa concentração e centralização do capital, em virtude da 
própria formatação das estruturas das empresas que passaram a se instalar no Brasil (RABELO, 2008). Isto também foi um dos elementos resultantes da elevada entrada de capitais estrangeiros no país, uma vez que com a vantagem competitiva de maior quantidade de capital disponível, essas empresas estrangeiras passaram a determinar a lógica de acumulação desse setor da economia.

33 Tem se então, a partir do Plano de Metas, a implantação de uma infraestrutura considerável, mas que ainda não abarcava todo o território nacional, junto à efetivação de uma indústria com dinamismo produtivo elevado, atrelado a uma agricultura com base produtiva caminhando para uma real modernização e com plena participação do BNDE na alocação de recursos para a expansão desses setores da economia brasileira.

\section{Ações articuladas do BNDES, Sistema Nacional de Crédito Rural e o desenvolvimento dos Complexos Agroindustriais}

34 É na transição temporal entre as décadas de 1960, 1970 e 1980, que se dão as outras grandes transformações socioespaciais brasileiras, que englobaram principalmente a agricultura e a indústria. Novamente, há uma forte influência do centro dinâmico do sistema capitalista, que culmina em alterações na base produtiva do país, vindo a alterar as relações sociais de produção, refletindo principalmente na fisionomia das esferas política e econômica.

35 A partir do governo militar de Castelo Branco, postulou-se uma política econômica seguindo os conselhos de Roberto Campos e Octávio Gouveia de Bulhões, pautando-se estritamente na visão monetarista da economia e na vinculação com empresas de capital estrangeiro. Sobre o início do governo militar e a relação deste com a instrumentalização do BNDE, Diniz (2004, p.29) aponta que:

Nos primeiros meses após o golpe de 1964, os Militares exibiam uma grande hostilidade contra o BNDE; afinal, o Banco foi braço fiel de governos populistas. Por decisão do poder executivo em 1964, ocorreu a extinção do Fundo de Reaparelhamento Econômico - que constituía a fonte primordial de recursos do BNDE na época. Sem estes recursos, a sobrevivência da instituição praticamente dependeria apenas dos retornos de seus empréstimos anteriores; na prática, representaria a quase estagnação de suas atividades.

Uma das criações desse período, foi o Plano de Ação Econômico do Governo (PAEG), que tinha por objetivo configurar o planejamento de ações voltadas para retomada do crescimento, pautadas na lógica monetarista. No entanto, o BNDE não foi incorporado diretamente nas diretrizes do PAEG (PINTO, 1967 apud DINIZ, 2004). Aliado a isso, houve um estreitamento com as concepções oriundas do Fundo Monetário Internacional (FMI), que davam ênfase a um Estado com postura de pouca intervenção na economia.

38 Seguindo essas bases, o governo apontou que um dos principais entraves para a volta do desenvolvimento da economia brasileira, era a inflação. De acordo com Resende (1990) a inflação chegou a taxa de $83,2 \%$ a.a. no início dos anos 1960 , e desta forma o governa vinculava essa taxa a expansão da demanda efetiva. Sendo assim, o objetivo principal do Estado neste momento era de frear o mercado consumidor comum, atuando principalmente no achatamento do salário dos trabalhadores de renda média. Aliado a isso, houve o enxugamento da oferta de crédito para as indústrias. Neste 
momento o crédito subsidiado passou a ser direcionado para a estrutura produtiva do setor primário exportador que, aliado à política de incentivos fiscais e exclusão de tarifas de exportação, fomentou o processo de diversificação da pauta de produtos exportáveis.

39 Esse cenário de desaceleração da produção industrial brasileira fez com que a burguesia industrial ficasse descontente com a situação. Outro fator agravante foi a própria manutenção dos altos níveis da inflação, ou seja, toda a política voltada para a retenção do poder de compra da população para diminuir a demanda acabou não trazendo os resultados esperados. Diante disso, houve uma mudança nos rumos da política econômica do governo brasileiro, tendo como base as ideias de Delfim Neto, que defendia uma intervenção estatal intensa na economia e um forte apoio ao capital nacional.

Mas ainda durante este período, o governo militar passou a criar diversas instituições com o intuito de viabilizar as suas ações, concentrados principalmente nos setores agrícola e industrial, sendo elas: o Fundo de Financiamento para a Aquisição de Máquinas e Equipamentos Industriais (FINAME), o Fundo de Financiamento de Estudos de Projetos e Programas (FINEP), o Organismo de Coordenação de Crédito Rural (CNCR) e o Fundo de Democratização do Capital das Empresas (FUNDECE) (MEDEIROS, 2006).

41 Desta forma, é dentro dessa perspectiva de criação de novas instituições para viabilizar uma reformulação na estrutura produtiva, que é criado o Sistema Nacional de Crédito Rural (SNCR). Ressaltamos que o crédito rural vem antes da formação do Sistema Nacional de Crédito Rural, sendo este criado em 1965, e o que havia antes eram institutos por produtos, que desta forma direcionavam as políticas públicas, que segundo Delgado (1985, p.21) "não abrangia o conjunto do setor agrícola primário exportador. Ademais, não se buscava, pela política agrícola, fixar nexos de relações interindustriais com agricultura e a indústria interna. " Portanto, havia um claro intuito de beneficiar oligarquias rurais tradicionais, em detrimento dos industriais e urbanos.

Somente a partir da efetivação da política de crédito rural, é que se passou a valorizar a mercadoria rural como um todo, e a base para isso foi o estabelecimento de um sistema bancário sistematizado (DELGADO, 1985). Sobre este sistema, Leite (2001, p.61) afirma que o mesmo foi:

43 [...] criado em 1965, através da Lei 4.829 (5/11/65), e regulamentado pelo Decreto 58.380 (10/5/66), era constituído pelo BACEN, BB, bancos regionais de desenvolvimento, bancos estaduais, bancos privados, caixas econômicas, sociedades de crédito, financiamento e investimento, cooperativas e órgãos de assistência técnica e extensão rural.

Assim, é institucionalizado um sistema nacional de crédito rural baseado na premissa de elevar o nível de produtividade agrícola, e proporcionar também o encadeamento produtivo integrando os demais setores da economia nacional, pois conforme afirma Delgado (1985), havia uma estreita relação do SNCR com o setor industrial, baseada no ato de financiar os meios de produção oriundos do referido setor. Como consequência dessa dinâmica de crédito rural, as instituições bancárias ampliaram bastante o seu raio de ação e expandindo-se espacialmente. Em se tratando da relação crédito rural, produtor e bancos, Delgado (1985, p.21) faz a seguinte observação: 
O crédito subsidiado é provido de maneira generosa e por intermédio do sistema bancário institucionalizado. A própria necessidade de financiamento se torna crescente, uma vez que tanto a elevação da capacidade produtiva quanto as necessidades de financiamento de capital de trabalho na agricultura passam a depender cada vez mais de recursos adquiridos no mercado. As fontes usuárias tradicionais, ligadas ao capital comercial, cedem lugar à rede bancária. E esta, ao se imiscuir no negócio rural, traz implícito um projeto de modernização que visa crescentemente a mudar a própria base técnica da agricultura.

De acordo com Spolador (2001), o Banco do Brasil foi uma das instituições bancárias que mais se beneficiou desse processo de intensificação do fluxo de capital na forma de crédito rural, chegando a obter a responsabilidade por $90 \%$ das operações de empréstimos destinados a produção agrícola.

47 Por intermédio de uma reforma fiscal e financeira promovida pelo governo de Castelo Branco, houve a regulamentação da relação com o sistema financeiro internacional e isso fez com que o "BNDE, após dezesseis anos contanto predominantemente com recursos governamentais de origem fiscal, procurou diversificar suas fontes (DINIZ, 2004, p.32)". Através da tabela 02 podemos ver que houve um claro aumento na captação de capitais externos para financiar os projetos setoriais submetidos ao BNDE e isso, consequentemente, teve um peso na materialização dos investimentos, principalmente no setor industrial, vindo a desencadear uma série de processos em outros setores da economia.

Tabela 02 - Evolução dos recursos externos do BNDE (1966-78)

\begin{tabular}{|l|l|}
\hline ANO & US\$ (Mil) \\
\hline 1966 & 9.547 \\
\hline 1967 & 11.207 \\
\hline 1968 & 1.336 \\
\hline 1969 & 28.410 \\
\hline 1970 & 22.083 \\
\hline 1971 & 17.084 \\
\hline 1972 & $78 . .399$ \\
\hline 1973 & 114.541 \\
\hline 1974 & 109.011 \\
\hline 1975 & 275.616 \\
\hline 1976 & 166.366 \\
\hline 1977 & 409.726 \\
\hline
\end{tabular}


Fonte: DINIZ (2004, P.32).

É neste momento que as engrenagens entre a agricultura, capital de crédito e indústria se fortalecem e passam a funcionar de maneira orquestrada, a partir de uma lógica de acumulação capitalista, que emanam fortemente os tentáculos dos Complexos Agroindustriais.

Há uma relevância desses aportes de capitais externos para esse processo de constituição e materialização espacial dos CAIs, pois "eles foram principalmente representados por contratos com entidades estrangeiras ou instituições internacionais, e eram basicamente destinados ao financiamento de importações de equipamentos (DINIZ, 2004, p.32)". De fato, esse capital externo alocado pelo BNDE foi em boa parte direcionado para a formação da estrutura produtiva dos diversos seguimentos pertencentes aos Complexos Agroindustriais.

A respeito da gênese desses complexos, Delgado (1985, p.34-35) faz uma brilhante análise, exposta da seguinte forma:

51 O final dos anos 60 é considerado como marco de constituição do chamado Complexo Agroindustrial brasileiro (CAI), denominado ainda por alguns autores de arrancada do processo de industrialização do campo. Esse processo caracteriza-se, fundamentalmente, pela implantação, no Brasil, de um setor industrial produtor de bens de produção para a agricultura. Paralelamente, desenvolve-se ou moderniza-se, em escala nacional, um mercado para produtos industrializados de origem agropecuária, dando origem à formação simultânea de um sistema de agroindústrias, em parte dirigido para o mercado interno e em parte voltado para a exportação.

52 Este autor teve a primazia de destacar além do avanço do setor industrial voltado para a estrutura técnica da agricultura, o desenvolvimento de agroindústrias para atender a demanda interna e externa por produtos industrializados, vinculados a uma origem agrícola (DELGADO, 1985).

53 Trazendo a discussão para a mudança na estrutura técnica da agricultura, a partir do prisma do crédito rural, a tabela 03 mostra como se deu a evolução da utilização de máquinas e insumos no referido setor, tendo como ponto de partida o ano de 1967, exatamente quando o país começa a acelerar o seu crescimento econômico.

Tabela 03 - Demonstração do índice simples da utilização dos insumos básicos de produção por parte do setor agrícola $-(1966=100)$

\begin{tabular}{|l|l|l|l|}
\hline Ano & Tratores (no) & Fertilizantes (ton.) & Defensivos (ton.) \\
\hline $\mathbf{1 9 6 7}$ & 110 & 159 & 126 \\
\hline $\mathbf{1 9 6 8}$ & 121 & 214 & 178 \\
\hline $\mathbf{1 9 6 9}$ & 132 & 225 & 201 \\
\hline $\mathbf{1 9 7 0}$ & 146 & 356 & 195 \\
\hline
\end{tabular}




\begin{tabular}{|l|l|l|l|}
\hline 1971 & 158 & 415 & 217 \\
\hline 1972 & 181 & 622 & 314 \\
\hline 1973 & 211 & 598 & 417 \\
\hline 1974 & 246 & 704 & 500 \\
\hline 1975 & 287 & 648 & 374 \\
\hline
\end{tabular}

Fonte: GRAZIANO DA SILVA (1981)

54 Quando se estabelece a reflexão sobre esse processo de modernização da agricultura e do desenvolvimento dos Complexos Agroindustriais, têm-se a impressão de que tudo isso ocorreu de forma uniforme em todos os espaços do território nacional, o que é um total engano. Houve de fato uma concentração espacial desses processos materializados principalmente nos Estados do Centro-Sul do país, abrangendo Minas Gerais, Goiânia, Rio de Janeiro, São Paulo, Paraná, Santa Catarina e Rio Grande do Sul, ficando o restante das regiões do Brasil a margem de toda essa dinâmica, exercendo apenas um papel periférico dentro da lógica espacial de acumulação gestada por esses complexos (DELGADO, 1985).

55 Quando levamos em consideração a distribuição dos recursos do BNDE, a partir de 1956 até 1965 , conforme destacado na tabela 04, veremos que há uma estreita relação entre o fluxo de capitais direcionados por esta instituição financeira durante esses anos, com a própria organização espacial desses complexos agroindustriais destacada por Delgado (1985).

Tabela 04 - Colaboração financeira autorizada pelo BNDE de acordo com regiões Geoeconômicas e UF - 1956/65

\begin{tabular}{|c|c|c|c|c|c|c|c|c|c|c|c|c|}
\hline Regiôes e UF & 1956 & 1957 & 1958 & 1959 & 1960 & 1961 & 1962 & 1963 & 1964 & 1965 & Total & $\begin{array}{c}\text { Part. } \\
\%\end{array}$ \\
\hline Norte & 84,2 & 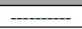 & 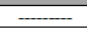 & 319,0 & 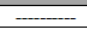 & 142,0 & 40,0 & 280,0 & 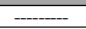 & $6.888,2$ & $7.754,4$ & 1,3 \\
\hline AM & 84,2 & 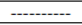 & 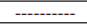 & 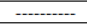 & 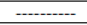 & -19-1 & 40,0 & 280,0 & $\ldots$ & $2.000,0$ & $2.404,2$ & 0,4 \\
\hline PA & & & & 319,0 & 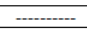 & 142,0 & & & & $2.889,2$ & $3.350,2$ & 0,5 \\
\hline Nordeste & 985,9 & 311,7 & 755,1 & 250,3 & 673,5 & 605,0 & 2570,0 & $2.200,0$ & $2.205,0$ & $13.869,7$ & $24.426,2$ & 4,0 \\
\hline MA & 12,6 & -1 & -1- & - - & - & - & ב- & -1 & 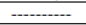 & 600,0 & 612,6 & 0,1 \\
\hline PI & 3,8 & & & & & & & & & $1.228,8$ & $1.232,6$ & 0,2 \\
\hline $\mathrm{CE}$ & 40,4 & 40,2 & 29,6 & 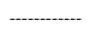 & 7,0 & 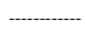 & -5 & --क- & 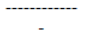 & $1.039,4$ & $1.156,6$ & 0,2 \\
\hline $\mathrm{RN}$ & 22,3 & 10,0 & -n.n- & ...n- & $\ldots$ & ...n- & -..-क & ...n- & - & 13,0 & 45,3 & 0,0 \\
\hline PB & 109,9 & 4,0 & 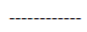 & 6,3 & 20,5 & 30,0 & 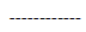 & 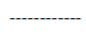 & 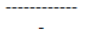 & 842,3 & $1.013,0$ & 0,2 \\
\hline PE & 364,7 & 54,3 & 40,0 & 60,0 & $\ldots$ & 400,02 & $2.500,0$ & $1.700,0$ & $2.205,0$ & $3.614,8$ & $10.938,8$ & 1,8 \\
\hline $\mathrm{AL}$ & 81,1 & & -7 & -2 & -2 & -7 & -1 & -7 & $-1+1-1$ & $1.134,9$ & $1.216,0$ & 0,2 \\
\hline $\mathrm{SE}$ & 20,0 & 18,7 & & & & & & & 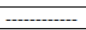 & 511,8 & 550,5 & 0,1 \\
\hline $\mathrm{BA}$ & 331,1 & 184,5 & 103,3 & 184,0 & 646,0 & 175,0 & 70,0 & 500,0 & & $4.884,7$ & $7.7078,6$ & 1,1 \\
\hline Sudeste & $11.391,4$ & $6.240,1$ & $10.499,2$ & $8.307,9$ & $13.955,6$ & $22.753,5$ & $19.110,8$ & $37.486,1$ & $88.676,0$ & $315.288,3$ & $533.708,9$ & 86,4 \\
\hline MG & $3.446,7$ & $3.467,0$ & $7.118,7$ & $1.695,5$ & $1.285,8$ & $8.606,0$ & $1.548,0$ & $5.275,1$ & $8.949,3$ & $106.091,5$ & $147.483,6$ & 23,9 \\
\hline ES & 377,8 & 0,0 & 51,0 & 632,8 & 95,1 & $1.546,0$ & 50,0 & $3.700,0$ & $9.700,0$ & $10.444,8$ & $26.597,5$ & 4,3 \\
\hline RJ & $2.561,9$ & 130,7 & 603,4 & $1.239,2$ & $1.398,8$ & $2.690,5$ & 260,0 & & $1.414,5$ & $7.669,9$ & $17.968,9$ & 2,9 \\
\hline Guanabara & $1.113,2$ & & 314,5 & 888,0 & & $1.611,0$ & 336,0 & 220,0 & 217,6 & $6.118,6$ & $10.818,9$ & 1,8 \\
\hline SP & $3.891,8$ & $2.642,4$ & $2.411,6$ & $3.852,4$ & $10.762,9$ & $8.300,0$ & $16.916,8$ & $\begin{array}{r}27.695,0 \\
\end{array}$ & $68.394,6$ & $184.963,5$ & $329.831,0$ & 53,4 \\
\hline SUL & $2.220,9$ & $1.740,2$ & 546,3 & 490,3 & 94,7 & $1.841,0$ & $1.205,3$ & $2.410,2$ & 160,0 & $12.211,5$ & $22.920,4$ & 3,7 \\
\hline PR & 633,0 & 60,0 & & 275,7 & & 331,0 & & 700,0 & 160,0 & $2.326,7$ & $4.486,4$ & 0,7 \\
\hline SC & 250,7 & -בו- & - & 1,8 & 79,7 & 650,0 & -1-4- & 90,2 & 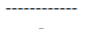 & 470,4 & $1.542,8$ & 0,2 \\
\hline RS & $1.337,2$ & $1.680,2$ & 546,3 & 212,8 & 15,0 & 860,0 & $1.205,3$ & 20,0 & - & $4.114,4$ & $9.991,2$ & 1,6 \\
\hline $\begin{array}{c}\text { Centro- } \\
\text { Oeste }\end{array}$ & 667,2 & 64,3 & 111,1 & 600,0 & 168,3 & 131,8 & $3.270,0$ & $1.346,0$ & $12.600,0$ & 641,0 & $19.599,7$ & 3,2 \\
\hline MT & 337,3 & 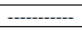 & $-\ldots$ & 600,0 & 168,3 & & & $1.346,0$ & 600,0 & 553,1 & $3.604,7$ & 0,6 \\
\hline GO & 329,9 & 64,3 & 111,1 & & & 131,8 & $3.270,0$ & & $12.000,0$ & 88,9 & $15.996,0$ & 2,6 \\
\hline $\begin{array}{c}\text { Não } \\
\text { discriminados }\end{array}$ & 31,3 & 89,4 & 330,0 & 65,0 & 20,0 & -1.n- & .1. & 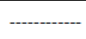 & …- & $8.493,5$ & $9.029,2$ & 1,5 \\
\hline BRASIL & $15.380,9$ & $8.445,7$ & $12.241,7$ & $10.032,5$ & $14.912,1$ & $25.473,3$ & $26.196,1$ & $43.722,3$ & $103.641,0$ & $357.394,2$ & $617.439,8$ & 100,0 \\
\hline
\end{tabular}

FONTE: Tavares et al 2010 
ervando a tabela 04, podemos ver que o fluxo de capital oriundo do BNDE fo direcionado praticamente para a região sudeste do Brasil, e esta absorveu $86,4 \%$ dos recursos dessa Instituição Financeira no período de 1956 a 1965, o que consequentemente, influenciou na concentração espacial dos complexos agroindustriais enfatizado por Delgado (1985), devido à composição do setor industrial que passou a ser gestado a partir desse período, juntamente com elementos correspondentes à infraestrutura, e que culminou no processo apontado por este autor. Nota-se que o estado de São Paulo foi a UF que mais captou recursos do BNDE no referido período, chegando a uma porcentagem de 53,4\% do total de capital autorizado por esta instituição financeira. A drenagem desse montante de capital reforçou a posição polarizadora desse estado no que se refere a organização espacial da estrutura produtiva setorial, e isso consequentemente gerou reflexos nos setores econômicos dos estados pertencentes ao centro sul do país. BNDE neste período apenas para os estados da Bahia e Pernambuco, no entanto, nos demais estados dessas regiões foram poucos recursos aprovados. Há uma relevância para o ano de 1965, quando rompeu-se com anos de ausência de capitais desse banco para grande parte dos estados das regiões norte e nordeste, mas que não foram o suficiente para dinamizar os diversos setores da economia em ambas as regiões, de forma a não incluí-las com intensidade no centro dinâmico dos complexos agroindustriais.

Assim, no que tange as regiões não incluídas efetivamente nesse processo de dinamização dos complexos agroindustriais, Guilherme Delgado faz a seguinte observação:

Quanto às regiões não atingidas de maneira predominante pela modernização - o Nordeste, de agricultura geralmente arcaica, e as regiões novas (fronteira agrícola) prevalecem processos produtivos grandemente heterogêneos e uma estrutura agrária dominada pela grande propriedade. A valorização do capital no setor agrícola não se dá aí, de forma necessária, por intermédio do CAI, mas pelo controle da propriedade fundiária. Esse é, pois, o lado conservador do projeto de modernização agrícola, que passa pela mediação política de acordo com complexas e instáveis alianças (DELGADO, 1985, p.42-43).

61 Além da própria concentração espacial do processo de modernização da agricultura e constituição dos CAIs, na sequência, o processo de concentração e centralização do capital vinculado às empresas pertencentes a esses referidos complexos. A tríade agricultura - crédito rural - indústria, cujo sistema de engrenagens fomentou a reprodução ampliada do capital, possibilitou que os fluxos de capital se centralizassem, passando a formatar as dimensões da relação agricultura - indústria. A respeito desse processo, Muller (1989, p.34) direciona a sua análise no seguinte sentido:

Com a integração indústria e agricultura no período 1969-80, deparamo-nos com empresas e grupos econômicos que influenciam poderosamente a dinâmica das atividades agrárias, com profundas repercussões em suas estruturas. Mas na própria agricultura surgem empresas e grupos econômicos, que com suas congêneres industriais, fazem parte do poder econômico com interesses nas atividades agrárias. $\mathrm{Na}$ indústria, no comércio e nas finanças é conhecido que a concentração e a centralização de capitais em empresas e grupos econômicos fazem com que estas unidades de capital 
se diversifiquem setorialmente sob a forma de multiplantas e multiprodutos. Ao se falar em agricultura, notadamente na brasileira, há, no mais das vezes, um enorme receio, quando não ceticismo, em aceitar que aí ocorrem processos semelhantes. Contudo, na agricultura brasileira, durante os anos 70 , surgiram grandes unidades centralizadas de capital.

63 Desta forma, as unidades empresariais centralizadoras do capital passam a imprimir sobre o espaço geográfico, uma formatação voltada para a manutenção de sua hegemonia dentro do processo de reprodução de capital. A agricultura se torna um dos elos da cadeia produtiva, ampliada verticalmente, e permite tanto a jusante quanto a montante uma diversificação produtiva do setor industrial.

64 Tal processo de integração agricultura - indústria, foi reforçado a partir dos anos 70 justamente pelas novas posições assumidas pelo BNDE, o que resultou em novas dinâmicas produtivas em todos os setores da economia brasileira, principalmente com a atuação desse banco atrelado ao II Plano Nacional de Desenvolvimento (DINIZ, 2004).

65 No que se refere a relação entre o BNDE e o II PND, Alem $(1998$, p.8) enfatiza que "com a crise do petróleo, que pressionou o balanço de pagamentos, o governo resolveu deslanchar o II PND com o objetivo de intensificar o programa de substituição de importações. Seguindo essa estratégia, o BNDES passou a financiar, principalmente, os setores de bens de capital e insumos". É importante destacar, conforme afirmação de Diniz (2004), que dentre os objetivos do II PND vinculados ao BNDE como agente interlocutor, estavam as metas de aumentar o fluxo de exportações tanto de produtos manufaturados quanto de produtos agrícolas.

Diante da proposta de aumentar a exportação desses produtos, havia a necessidade de um maior fluxo de crédito rural, e desta forma a tabela 05 mostra a evolução do montante de capital direcionado ao setor produtivo agrícola durante a década de 70, e terminando no início da década de 1990, com uma queda considerável na liberação de crédito rural.

Tabela 05 - Total anual de crédito rural no Brasil e sua respectiva finalidade

\begin{tabular}{|l|l|l|l|l|}
\hline \multirow{2}{*}{ Ano } & \multirow{2}{*}{ Total (milhões de reais)* } & \multicolumn{3}{|l|}{ Participação no total de crédito concedido (em \%) } \\
\cline { 3 - 6 } & & Custeio & Investimento & Comercialização \\
\hline $\mathbf{1 9 7 0}$ & 33.137 & 44,60 & 21,14 & 28,25 \\
\hline $\mathbf{1 9 7 1}$ & 38.329 & 43,52 & 29,50 & 26,98 \\
\hline $\mathbf{1 9 7 2}$ & 47.387 & 41,63 & 33,08 & 25,29 \\
\hline $\mathbf{1 9 7 3}$ & 67.006 & 42,70 & 33,09 & 24,21 \\
\hline $\mathbf{1 9 7 4}$ & 82.862 & 45,02 & 30,27 & 24,70 \\
\hline $\mathbf{1 9 7 5}$ & 120.816 & 43,83 & 31,25 & 24,92 \\
\hline $\mathbf{1 9 7 6}$ & 123.775 & 42,20 & 32,42 & 25,38 \\
\hline $\mathbf{1 9 7 7}$ & 110.504 & 47,29 & 24,26 & 28,45 \\
\hline
\end{tabular}




\begin{tabular}{|l|l|l|l|l|}
\hline $\mathbf{1 9 7 8}$ & 112.353 & 47,69 & 24,97 & 27,34 \\
\hline $\mathbf{1 9 7 9}$ & 140.011 & 50,30 & 24,98 & 24,72 \\
\hline $\mathbf{1 9 8 0}$ & 133.898 & 56,58 & 18,76 & 24,66 \\
\hline $\mathbf{1 9 8 1}$ & 116.139 & 58,65 & 15,46 & 25,90 \\
\hline $\mathbf{1 9 8 2}$ & 112.465 & 64,33 & 13,12 & 22,56 \\
\hline $\mathbf{1 9 8 3}$ & 84.896 & 62,18 & 16,69 & 21,12 \\
\hline $\mathbf{1 9 8 4}$ & 51.856 & 70,48 & 12,31 & 17,20 \\
\hline $\mathbf{1 9 8 5}$ & 73.947 & 71,11 & 12,96 & 15,93 \\
\hline $\mathbf{1 9 8 6}$ & 110.267 & 55,94 & 32,05 & 12,01 \\
\hline $\mathbf{1 9 8 7}$ & 86.924 & 70,16 & 17,10 & 12,74 \\
\hline $\mathbf{1 9 8 8}$ & 61.338 & 68,02 & 16,02 & 15,96 \\
\hline $\mathbf{1 9 8 9}$ & 56.012 & 79,99 & 10,51 & 9,51 \\
\hline $\mathbf{1 9 9 0}$ & 32.000 & 74,86 & 10,96 & 18 \\
\hline
\end{tabular}

Fonte: Bacha (2012, p.62)

Nota: *Dados do Banco Central do Brasil, considerando o deflacionamento pelo IGP-DI.

67 Em relação a esta tabela, observa-se em linhas gerais que o direcionamento maior de capital está vinculado ao custeio, com larga vantagem sobre as outras duas finalidades. Esse destaque do custeio pode ser explicado pelo alto custo produtivo da maior parte das estruturas de produção que envolve o setor agrícola. Em se tratando dos valores destinados ao investimento e a comercialização, podemos ver um equilíbrio com uma leve diferença a favor do primeiro, cujo principal uso do capital de crédito está vinculado à compra de máquinas, construção de armazéns, instalação de novas tecnologias produtivas, dentre outros. Já a comercialização toma a frente em volume de capital se comparado ao de investimento, a partir do ano de 1977, prolongando esse domínio até meados de 1985.

Há clara evolução nos valores de capital para o setor agrícola a partir de 1970, chegando ao seu ápice no ano de 1976. Logo após, há uma tendência à queda, influenciada pela crise do petróleo e por medidas de contenção executadas pela política monetária brasileira (DELGADO, 1985). No entanto, ocorre nova elevação entre 1979 e 1980, vinculado à própria fase expansiva do Ciclo Médio (RANGEL, 1983), um dos últimos arranques do desenvolvimento econômico brasileiro, influenciado pelas dinâmicas favoráveis do comércio exterior naquele momento.

69 A orientação expansionista é retomada com menor vigor em 1978 e 1979, à luz do discurso oficial do governo de prioridade ao setor agrícola, para ser revertida novamente a partir de 1980. Essa nova reversão - que se mantém cada vez mais acentuada em 1981 e 1982, com condições mais adversas, quer do próprio contexto da 
economia brasileira, quer das suas relações críticas com a economia internacional (DELGADO, 1985, p.79)

70 Logo após esse período de 1982, a tendência à queda se estabelece, apresentando como interrupção apenas o ano de 1986, e logo em seguida mantendo o decrescimento do fluxo de capital de crédito para o referido setor.

71 Todo esse fluxo de capital estava vinculado a uma proposta de desenvolvimento que alavancasse o Brasil no cenário internacional. Diante disso, o Estado brasileiro tinha um papel preponderante de fazer a ponte entre o capital e as forças produtivas do país. "O Estado opera sobretudo na esfera da intermediação financeira, e na formulação e implementação de uma vasta gama de políticas econômicas concernentes às atividades industriais, agrárias e de abastecimento (MULLER, 1989, p.33-34)".

72 É importante destacarmos que, com a intensificação da crise do petróleo no final da década de 70, a elevação das taxas de juros e escassez das fontes de financiamento internacional, o governo brasileiro adotou algumas medidas que contaram com o apoio do BNDE, conforme afirma Bel Filho et al. (2012, p.94):

o Brasil, importador líquido de petróleo e devedor internacional, foi afetado severamente, sofrendo déficits crescentes no balanço de pagamento. O governo, visando estancar esse movimento, instituiu o III Plano Nacional de Desenvolvimento (III PND), cujos esforços se concentraram nas atividades exportadoras e/ou poupadoras de divisas. Em 1979, foi lançado o Próalcool, com o objetivo de reduzir as importações de petróleo e, com isso, diminuir a pressão sobre a balança comercial. Coube ao BNDES ser o agente do respectivo programa. A partir de então, o BNDES passou a financiar a atividade agropecuária, pois atuou tanto nas operações industriais, com financiamento à implantação de destilarias, como nas operações rurais, financiando as lavouras de cana-de-açúcar.

74 No entanto, a partir do início dos anos $80^{7}$, "o modelo de desenvolvimento fortemente embasado no financiamento externo "fácil" entrou em colapso: as taxas de juros internacionais elevaram-se substancialmente devido à alta unilateral da taxa americana (DINIZ, 2004, p.43)". Com essa conjuntura econômica, durante a década de 1980, o BNDE teve que se adequar às novas diretrizes impostas pelo Estado brasileiro, que priorizavam naquele momento a estabilidade econômica. Desta forma, este banco não conseguiu se estabelecer como uma instituição capaz de fornecer subsídios para sanar determinados problemas econômicos da década de 1980 (CURRALEIRO, 1998), colocando-se apenas na posição de "desembolsar recursos que visavam o saneamento de empresas públicas e privadas [...] O BNDES ficou sem uma clara definição de prioridades entre os anos de 1985 a 1990 (DINIZ, 2004, p.46-47)". Conforme apontado por esta mesma autora, no ano de 1982, por intermédio do Decreto Lei nº 1940, o BNDE passou a exercer a função de provedor do desenvolvimento social e desde então foi acrescido o "S" na nomenclatura do banco.

Diante do agravamento da crise e da falta de recursos para investimentos, principalmente na segunda metade dos anos 80 , a maior parte das unidades produtivas pertencentes aos CAIs não conseguiram manter a dinâmica de equilíbrio dentro das suas esferas financeiras, apenas com alguns ramos produtivos mantendo-se dinâmicos. A tabela 06 apresenta a produção de alguns ramos do setor agroindustrial brasileiro para a década de 1980, para dar maior visibilidade ao processo que destacamos acima. 
Tabela 06 - Total da produção de alguns ramos do setor agroindustrial

\begin{tabular}{|c|c|c|c|c|c|}
\hline Ano & $\begin{array}{l}\text { Produção de } \\
\text { máquinas agrícolas } \\
\text { automotrizes } \\
\text { (unidade) }\end{array}$ & $\begin{array}{l}\text { Produção de } \\
\text { leite } \\
\text { pasteurizado } \\
\text { (1000 litros) }\end{array}$ & $\begin{array}{l}\text { Aves } \\
\text { abatidas } \\
(1000 \\
\text { cabeças) }\end{array}$ & $\begin{array}{l}\text { Carne de aves } \\
\text { congeladas } \\
\text { exportadas } \\
\text { (toneladas) }\end{array}$ & $\begin{array}{l}\text { Carne bovina } \\
\text { congelada } \\
\text { exportada } \\
\text { (toneladas) }\end{array}$ \\
\hline 1980 & 77.478 & 2880676 & 615627 & 168713 & 5362 \\
\hline 1981 & 53.708 & 2930222 & 723567 & 293933 & 44980 \\
\hline 1982 & 42.069 & 3112006 & 798426 & 301793 & 93110 \\
\hline 1983 & 30.399 & 3084602 & 795462 & 289301 & 117405 \\
\hline 1984 & 56.232 & 4235859 & 753116 & 280284 & 110604 \\
\hline 1985 & 56.215 & 4183400 & 745774 & 277142 & 135096 \\
\hline 1986 & 68.970 & 4203580 & 757588 & 226622 & 74540 \\
\hline 1987 & 62.668 & 4680259 & 832082 & 210841 & 60341 \\
\hline 1988 & 51.476 & nd & nd & nd & nd \\
\hline 1989 & 43.680 & nd & nd & nd & nd \\
\hline
\end{tabular}

FONTES: Mapa geral das industrias do Brasil. In: Séries estatísticas retrospectivas. Ed. fac.sim. Rio de Janeiro: IBGE, 1986.v.2: O Brasil, suas riquezas naturais, suas indústrias, t.3.2.pt.p.150; Anuário Estatístico da Indústria Automobilística Brasileira 2001. São Paulo: Associação Nacional dos Fabricantes de Veículos Automotores, 2001. Ano-base 1957-2000. Estatísticas históricas do Brasil: séries econômicas, demográficas e sociais de 1550 a 1988. 2. ed. rev. e atual. do v. 3 de Séries estatísticas retrospectivas. Rio de Janeiro: IBGE, 1990. Organizado pelo autor.

76 Podemos observar, através da tabela 06, que a quantidade produzida de máquinas agrícolas automotrizes teve uma queda relativamente grande nos primeiros anos da década de 1980 que, provavelmente, está relacionada a queda do fluxo de crédito rural voltado para a finalidade de investimento. "Esse padrão de financiamento com base no crédito subsidiado foi desmontado em expressão a partir da crise da dívida pública da entrada dos anos 1980 (GONÇALVES, 2012, p.3)".

77 Se por um lado o crédito subsidiado oriundo do Estado se tornou escasso, outras formas de financiamento da agricultura acabaram surgindo. Novamente, os grandes grupos agroindustriais viram como promissor esse cenário de escassez de recursos para os produtores agrícolas, e a partir disso, passaram a fazer a função de alocadores de capital para estes fins. 0 contrato Soja Verde, foi um dos elementos criados com essa função de financiar a produção desse grão, conforme aponta Gonçalves et.al. (2005, p. 69)

78 [...] representa o instrumento das empresas agroindustriais e de exportação para garantir a compra antecipada de pelo menos parcela da matéria-prima que as permitam assumir compromissos tanto no mercado interno como externo, tendo sido 
generalizado no complexo soja, face ao seu dinamismo frente a oportunidades crescentes de negócios no cenário internacional.

79 Desta forma, as saídas para o afluxo de capital de crédito subsidiado são postas a partir de uma lógica altamente financeirizada, com intensa participação de grandes empresas do complexo agroindustrial. Dentro dessas medidas contencionistas executadas com o aval do Estado brasileiro, com o claro objetivo de ampliar o aporte de capitais e estabilizar o sistema de financiamentos, estava o processo de privatizações $^{8}$, que tiveram plena participação do BNDES. Isso demonstra como houve uma alteração na postura do BNDES durante os anos 1980, bastante diferente da atuação do banco desde a sua criação até final da década de 1970 quando grandes volumes de capital foram direcionados para projetos de desenvolvimento setorial da economia brasileira (CURRALERO, 1998).

80 Consequentemente, grande parte dos complexos agroindustriais foram afetados por esse novo perfil do banco, o que impossibilitou a efetivação de grandes investimentos para a ampliação das estruturas produtivas. No entanto, a própria política de estabilização dessa década, que gerou uma redução do crédito rural subsidiado, gerou novas frentes de reprodução de capital para grandes empresas desses complexos, na medida em que estas passaram a atuar de forma a alocar capital financeiro para os produtores rurais.

\section{Considerações Finais}

81 O BNDES apresentou um papel fundamental na formação e desenvolvimento dos Complexos Agroindustriais no Brasil, justamente por sua capacidade de alocação de capital e direcionamento dos investimentos. Essa instituição financeira possibilitou a implantação de infraestruturas nesse país, que sem as quais não seria possível atingir um determinado nível de desenvolvimento dos setores produtivos.

82 Num primeiro momento o BNDES é direcionado a financiar projetos voltados principalmente para o setor de energia, seguindo assim as diretrizes do Plano de Metas que considerava essencial o fortalecimento da indústria nacional, e consequentemente para isso seria necessário esse aporte energético para a efetivação de tais objetivos. Como o processo de industrialização via substituição de importações já havia se iniciado em 1930, o Brasil já contava com um grande número de pessoas que migraram das áreas rurais para os centros urbanos, e por isso a pressão por produção de alimentos se intensificava sobre o setor agrícola. É a partir desse momento que o setor agrícola brasileiro começa a passar por um processo de modernização, importando máquinas, equipamentos e insumos necessários para atingir um determinado patamar de produção que satisfizesse a demanda urbana crescente.

83 Aliado a uma conjuntura macroeconômica favorável, juntamente com um Estado com viés nacional desenvolvimentista, o BNDES passou a financiar indústrias produtoras de equipamentos e insumos para a agricultura, materializando ainda a proposta de substituição de importações. Ainda durante esse período, anos 60 e início dos anos 70, essa instituição passa a fornecer crédito para implantação de agroindústrias, integrando ainda mais a cadeia produtiva entre a indústria e a agricultura. Ademais, ainda no que se refere a projetos de infraestrutura, o BNDES forneceu o capital necessário para os investimentos nas rodovias, contribuindo para a expansão da fronteira agrícola. 
84 os anos 1960, concentraram-se na região Sudeste do Brasil, vindo a fortalecer ainda mais os setores produtivos dessa região, com destaque para o Estado de São Paulo, o que resultou em uma concretização da polarização econômica dessa unidade da federação. De fato, isso acabou sendo um dos entraves para o desenvolvimento dos CAI's nas demais regiões do país durante esse período, mas que no decorrer dos anos, em função de novas configurações políticas e macroeconômicas, fez emergir novas dinâmicas nas relações de produção e nas forças produtivas dessas áreas, resultando na implantação de unidades produtivas vinculadas aos CAI's.

Portanto, até os primeiros anos da década de 1980, o BNDES foi peça chave na construção dos CAI's no Brasil, dinamizando indústria e agricultura, integrando os elos das cadeias produtivas desses dois setores, e consequentemente proporcionando novas dinâmicas geoeconômicas, preparando inclusive o cenário de financeirização da agricultura que se desenharia principalmente na segunda metade dos anos 1980.

\section{BIBLIOGRAFIA}

BACHA, C.J.C. Economia e política agrícola no Brasil. São Paulo: Atlas, 2012. 226 p.

BEL FILHO, Egmar, LIMA, Jaldir Freire et al. Apoio do BNDES à agroindústria: retrospectiva e visão de futuro. In: BNDES. BNDES 60 anos: perpsectivas setoriais. Volume II. Brasília: BNDES, 2012.

BENEVIDES, Maria Victoria. A UDN e o udenismo: ambiguidades do liberalismo brasileiro. Rio de Janeiro: Paz e Terra, 1981.

BELUZZO, Luiz Gonzaga Mello; COUTINHO, Luciano. Desenvolvimento e inserção externa nos anos 90: uma crítica à visão de Gustavo Franco. Texto preparado para o IEDI, novembro, mimeo, 1996.

COUTO, Ana Cristina Lima; TRINTIM, Jaime Graciano. O papel do BNDES no financiamento da economia brasileira. Encontro Internacional da Associação Keynesiana Brasileira, v. 5, 2012.

CURRALERO, Cláudia Regina Baddini. A atuação do Sistema BNDES como instituição financeira de fomento no período 1952/1996. Campinas: Unicamp. IE, 1998. (Dissertação, Mestrado).

DELGADO, Guilherme da C. Capital Financeiro e Agricultura no Brasil. São Paulo: Unicamp/Cone, 1985.

DINIZ, A.N. BNDES: de agente de desenvolvimento a gestor da privatização - 1952-2002.

Dissertação (Mestrado em Economia) - Universidade Estadual de Campinas, Campinas, 2004.

DRAIBE, Sônia. Rumos e metamorfoses: um estudo sobre a constituição do Estado e as alternativas da industrialização no Brasil, 1930-1960. Rio de Janeiro: Paz e Terra, 1985.

GONÇALVES, José Sidnei. Agricultura Sob a Égide do Capital Financeiro: Passo rumo ao aprofundamento do desenvolvimento do agronegócio. São Paulo, v.35, no 4 . Abril de 2005.

GONÇALVES, José Sidnei; MARTIN, Nelson Batista; RESENDE, José Venâncio; VEGRO, Celso Luis R. Novos títulos financeiros do agronegócio e novo padrão do financiamento setorial. In: Informações Econômicas. São Paulo, v, 35, n.7, jul.2005, p. 63-90 
GRAZIANO DA SILVA, José. A nova dinâmica da agricultura brasileira. Campinas: Unicamp-IE, 1996.

HIPPOLITO, Lucia. De raposas e reformistas: o PSD e a experiência democrática brasileira (1945-64). Editora Paz e Terra, 1985.

IBGE. Instituto Brasileiro de Geografia e Estatística. 2017. Sistema IBGE de Recuperação Automática - SIDRA.

KAGEYAIVIA, A. (Org.). O Novo Padrão Agrícola Brasileiro: Do Complexo Rural aos Complexos Agroindustriais. Campinas, 1987.

LEITE, Sérgio. (org.). Políticas Públicas e Agricultura no Brasil. Porto Alegre. Editora da Universidade, UFRGS, 2001, pág. 61.

MACHADO FILHO, C. A. P. et al. Agribusiness Europeu. São Paulo: Pioneira, 1996

MAMIGONIAN, Armen. Kondratieff, ciclos médios e organização do espaço. Geosul, v. 14, n.

MARAFON, Gláucio José. Industrialização da agricultura e formação do complexo agroindustrial no Brasil. Geo UERJ, n. 3, 1998.

MEDEIROS, Marlon Clovis. Industrialização e agricultura: o complexo agroindustrial do arroz de Santa Catarina. Edunioeste, 2006.

MÜLLER, Geraldo. Agricultura e industrialização do campo no Brasil. Revista de Economia Política, v. 2, n. 6, p. 47-77, 1982.

MÜLLER, G. Complexo Agroindustrial e Modernização Agrária. São Paulo: Hucitec: EDUC. 1989. $149 \mathrm{p}$

RABELO, Ricardo Fonseca. Plano de Metas e consolidação do capitalismo industrial no Brasil. Economia \& Gestão, v. 2, n. 4, 2008. Disponível em: < http://periodicos.pucminas.br/index.php/ economiaegestao/article/view/101> Acesso em: 09 de maio de 2017. 28, p. 152-157, 1999.

RANGEL, Ignácio. Introdução ao estudo do desenvolvimento econômico brasileiro. Salvador: Universidade da Bahia, 1957

RANGEL, Ignácio. A história da dualidade brasileira. Revista de Economia Política, v. 1, n. 4, p. 5-34, 1981.

RANGEL, Ignácio. O ciclo médio e o ciclo longo no Brasil. Ensaios FEE, v. 3, n. 2, p. 31-42, 1983.

RANGEL, Ignácio. O quarto ciclo de Kondratiev. Revista de Economia Política, v. 10, n. 4, p. 40, 1990.

RESENDE, André Lara (1990). Estabilização e Reforma (1964-1967) IN ABREU, Marcelo de Paiva (org.) A Ordem do Progresso: cem anos de política econômica republicana, 1889-1989. Rio de Janeiro: Elsevier, $31^{\underline{a}}$ reimpressão.

SILVA, José Graziano da. Complexos agroindustriais e outros complexos. Revista da Associação Brasileira de Reforma Agrária, v. 21, n. 3, 1991.

SINGER, Paul. Desenvolvimento e crise. Rio de Janeiro: Paz e Terra, 1982.

SOUZA, Nilson Araújo de. Economia brasileira contemporânea: de Getúlio a Lula. 2.ed. - São Paulo: Atlas, 2008.

SPOLADOR, Humberto Francisco Silva. Reflexões sobre a experiência brasileira de financiamento da agricultura. 2001. Tese de Doutorado. Universidade de São Paulo. 
TAVARES, M. C. et al. O papel do BNDE na industrialização do Brasil - Os anos dourados do desenvolvimentismo, 1952-1980. Memórias do desenvolvimento,n.4, p. 1-331, 2010.

\section{NOTAS}

1. A partir desse período inicia-se uma nova fase, caracterizada por uma intensificação do processo de financeirização da agricultura, em virtude de uma nova conjuntura política e econômica no Brasil, com fortes influências do neoliberalismo. Portanto, as discussões a partir dos anos 1980 devem ser abordadas em um próximo artigo.

2. É importante destacar que existem duas correntes de interpretação sobre o Complexo Agroindustrial brasileiro. Uma delas é a de um macro Complexo Agroindustrial, trabalhado por Müller (1982) e Machado Filho et al (1996). A outra base de interpretação é a de Kageyama (1987) e Silva (1991), que além de diferenciarem os processos de modernização e industrialização da agricultura brasileira, apresentam uma análise histórica da dissolução do Complexo Rural (Rangel, 1957) e formação dos Complexos Agroindustriais. Para este trabalho, foram utilizados elementos teóricos das duas bases de interpretação, uma vez que ambas, apesar de diferenças na abordagem, apresentam contribuições significantes para o entendimento do processo. Para maiores detalhes sobre essas correntes ver em Marafon (1998).

3. Em sua criação, no ano de 1952, esse banco chamava-se Banco Nacional de Desenvolvimento Econômico (BNDE), vindo a ter o S no nome somente em 1982, a partir da sua vinculação a uma proposta de desenvolvimento também na esfera social. Portanto, ao tratarmos da conjuntura até 1982 , trataremos o banco com a sigla BNDE.

4. Conforme destaca Diniz (2004, p.18) “os setores prioritários em que o banco passou a atuar foram o reequipamento dos portos, ferrovias, projetos de expansão de energia hidroelétrica e siderurgia. No primeiro quinquênio da década de 50, o BNDE ficou conhecido como o Banco da Eletricidade".

5. O BNDE "financiou 46 projetos até 1960 , sendo que os mais importantes foram o de Três Marias, Furnas, complexos de usinas de São Paulo Light e a ampliação de Paulo Afonso (DINIZ, 2004, p.25)".

6. “O plano foi executado quase na íntegra. Dos 355,8 bilhões de cruzeiros previstos para investirse no período $1957-61,93,4 \%$ se destinavam ao investimento em energia, transporte e indústria de base (onde se incluía siderurgia, cimento, metais não ferrosos, fertilizantes, ou seja, insumos básicos fundamentais) (SOUZA, 2008, p.30)".

7. Ver uma análise mais detalhada e incisiva do período em Beluzzo e Coutinho (1996)

8. Ver com maiores detalhes deste processo em Diniz (2002).

\section{RESUMOS}

O presente trabalho possui como objetivo traçar uma análise, com viés geográfico, sobre o papel do Banco Nacional de Desenvolvimento Econômico e Social (BNDES), na formação dos Complexos Agroindustriais (CAI's) no Brasil. O BNDES é uma importante instituição financeira criada em 1952, e que desde então direciona os fluxos de investimento para os setores produtivos. Para isto foi utilizado como instrumento metodológico a pesquisa bibliográfica, uma vez que esse é um 
trabalho de cunho estritamente teórico, que visa focar nas dinâmicas geoeconômicas de tal instituição financeira e do respectivo complexo. Os resultados apontam que o BNDES teve um papel importante na gênese e desenvolvimento dos CAI's, principalmente a partir dos anos 1960, uma vez que possibilitou a materialização das infraestruturas (energia e estradas, por exemplo), unidades produtivas industriais fornecedoras de equipamentos e insumos para a agricultura, acrescido de unidades produtivas agroindustriais processadoras de matérias-primas do setor agrícola. Ademais, tal quadro de investimentos do banco se construiu a partir de uma conjuntura política caracterizada por um Estado que havia adotado uma postura desenvolvimentista, que culminou na estruturação de elementos macroeconômicos voltados para a continuidade do processo de industrialização.

El presente trabajo tiene como objetivo trazar un análisis, con sesgo geográfico, sobre el papel del Banco Nacional de Desarrollo Económico y Social (BNDES), en la formación de Complejos Agroindustriales (CAI) en Brasil. BNDES es una importante institución financiera creada en 1952, y desde entonces dirige los flujos de inversión hacia los sectores productivos. Para este propósito, la investigación bibliográfica se utilizó como una herramienta metodológica, ya que este es un trabajo estrictamente teórico, cuyo objetivo es centrarse en la dinámica geoeconómica de dicha institución financiera y el complejo respectivo. Los resultados muestran que el BNDES tuvo un papel importante en la génesis y el desarrollo de los CAI, principalmente a partir de la década de 1960, ya que permitió la materialización de las infraestructuras (energía y carreteras, por ejemplo), unidades de producción industrial que suministran equipos e insumos para agricultura, más unidades de producción agroindustrial que procesan materias primas en el sector agrícola. Además, el marco de inversión del banco se construyó sobre la base de una situación política caracterizada por un Estado que había adoptado una postura desarrollista, que culminó en la estructuración de elementos macroeconómicos destinados a la continuidad del proceso de industrialización.

The Banco Nacional de Desenvolvimento Econômico e Social (BNDES) is an important financial institution for Brazil. It was established in 1952 and has directed the investment flows to productive sectors since then. This work, thus, aims to draw a geographical analysis of the role of BNDES in the construction of the Agroindustrial Complexes (AICs) in the country . For this, the bibliographic search was used as a methodological instrument because this is theoretical work that aims to focus on the geoeconomic dynamics of such a financial institution and those complexes. The results indicate that BNDES played an important role in the genesis and development of these AICs, mainly from the 60 's, since it made possible the materialization of the infrastructures (such as energy and roads), industrial production units that are equipment suppliers and inputs for agriculture, plus agro-industrial production units that processes raw materials from the agricultural sector. Moreover, the investment framework of this bank, which influenced the joining of these two productive sectors, was built on a political conjuncture characterized by a state that had adopted a developmental stance, which culminated in a structuring of macroeconomic elements aimed at this objective.

\section{ÍNDICE}

Keywords: BNDES; Agroindustrial Complexes; Geoeconomics; Investment

Palabras claves: BNDES; Complejos agroindustriales; Geoeconomía; Inversión

Palavras-chave: BNDES; Complexos Agroindustriais; Geoeconomia; Investimento. 


\section{AUTORES}

\section{ALESSANDRO VICELI}

Mestre e Doutorando em Geografia pela Universidade Estadual do Oeste do Paraná - Campus de Francisco Beltrão. Email: alevicelli@hotmail.com

\section{MARLON CLÓVIS MEDEIROS}

Doutor em Geografia. Universidade Estadual do Oeste do Paraná - Campus de Francisco Beltrão.

Professor. Email: marlonmedeiros@hotmail.com 